\title{
MODEL ORGANISMS ILLUMINATE HUMAN GENETICS AND DISEASE
}

\author{
Veronica van Heyningen \\ MRC Human Genetics Unit, Edinburgh, United Kingdom
}

The success of the Human Genome Project has catalyzed an amazing explosion of molecular insight into the causes of human disease. However, identifying the genes implicated in disease is just the first step on the long road to understanding the biology of the anomaly and to designing successful therapeutic intervention. Although human populations provide a superb source of carefully described, diverse mutations that can tell us much about normal and abnormal gene function, biological experimentation in humans is very difficult. Model systems from yeast to mouse are therefore contributing widely to our understanding of disease mechanisms and pointing the way to rational therapies.

It is becoming increasingly clear that there is at least some genetic contribution to most human disease. However, even where it does not play a part in disease aetiology, genetics can be used to unravel biochemistry and physiology. By perturbing normal pathways at discrete points, gene mutations provide excellent tools for dissecting biochemical and developmental pathways and molecular interactions in many different organisms. A major insight to emerge from the various genome projects (Table 1), is the existence of an amazing degree of conservation among genes that participate in similar pathways across a wide spectrum of phyla. This means that we can often use a variety of simpler, experimentally more amenable organisms to understand human disorders.

For example, knowing how yeast controls DNA replication and repair, and entry into the cell cycle, has provided insights into the mecha-

Address correspondence and reprint requests to: Veronica van Heyningen, Head of Cell Genetics Section, MRC Human Genetics Unit, Western General Hospital, Crewe Road, Edinburgh EH4 2XU, United Kingdom. Tel: 44-131-4678405; Fax: 44-131-340-2620; e-mail: V.vanheyningen@ hgu.mrc.ac.uk. nisms of cancer and cellular signaling. Studies of the nematode worm Caenorhabditis elegans and the fruitfly Drosophila melanogaster have revealed many of the mysteries of cell biology, differentiation, and development, since genes utilized in these simpler organisms are often astonishingly similar to those in mouse and human. Clearly, there is an increase in complexity from worms to vertebrates-from the $10^{3}$ cells of $C$. elegans to the $10^{14}$ cells of human. Within vertebrates, zebrafish are much easier to grow and manipulate than mammals and are providing new insight into development. For close functional parallels, however, we continue to look to mammals, and the laboratory mouse is still the organism of choice for the study of human disease. Naturally occurring mutants as well as mouse models created by molecular manipulation provide detailed insight into many human pathologies.

Even when genes implicated in human disease are unequivocally identified, several different model systems are often needed to understand sufficiently the molecular pathology before the design of rational therapy can be considered. Here, a few examples are presented to illustrate the usefulness of this "phylum-hopping" approach to understanding human disease mechanisms.

\section{LESSONS FROM YEAST: CONTROL OF CELL CYCLE AND DNA REPAIR}

Saccharomyces cerevisiae (budding yeast) and Schizosaccharomyces pombe (fission yeast) are eukaryotes with readily accessible genetics, allowing the creation, selection, and isolation of a wealth of mutants. Many fundamental aspects of cell division control were first studied in detail in yeast. Yeast cells divide very fast when nutrients 
TABLE 1. Genome programs and biological advantages of different model organisms

\begin{tabular}{|c|c|c|}
\hline Organism & Genome Analysis in Progress & Biological Analysis \\
\hline Escherichia coli & Genome sequence (nearly complete) & Genetics, biochemistry \\
\hline $\begin{array}{l}\text { Saccharomyces cerevisiae } \\
\text { (budding yeast) }\end{array}$ & Genome sequence (complete) & $\begin{array}{l}\text { Genetics, genetic manipulation, cell biology, } \\
\text { biochemistry }\end{array}$ \\
\hline $\begin{array}{l}\text { Caeñorhabditis elegans } \\
\text { (nematode worm) }\end{array}$ & $\begin{array}{l}\text { Genome sequence } \\
\qquad(\sim 50 \% \text { complete })\end{array}$ & $\begin{array}{l}\text { Development, cell biology, genetics, genetic } \\
\text { manipulation }\end{array}$ \\
\hline $\begin{array}{l}\text { Drosophila melanogaster } \\
\quad \text { (fruitfly) }\end{array}$ & Genome sequence & $\begin{array}{l}\text { Genetics, development, cell biology, genetic } \\
\text { manipulation }\end{array}$ \\
\hline $\begin{array}{l}\text { Fugu rubipiens } \\
\text { (puffer fish) }\end{array}$ & $\begin{array}{l}\text { Genome analysis-telescoped } \\
\text { genome ( } 1 / 8 \text { of human) }\end{array}$ & Comparative mapping, genomic organization \\
\hline Danio rerio (zebrafish) & Genome mapping of mutants & Developmental mutant selection (vertebrate) \\
\hline Mus musculus (mouse) & $\begin{array}{l}\text { Genome mapping } \\
\text { Gene mapping, isolation, and } \\
\text { identification }\end{array}$ & $\begin{array}{l}\text { Genetics, development, and developmental } \\
\text { manipulation; cell biology, physiology, } \\
\text { some disease models. Comparative mapping }\end{array}$ \\
\hline Homo sapiens (human) & $\begin{array}{l}\text { Genome mapping and sequence } \\
\text { Gene mapping, isolation, and } \\
\text { identification-large scale }\end{array}$ & $\begin{array}{l}\text { Genetics, physiology, well-characterized } \\
\text { variant and disease phenotypes, and disease } \\
\text { progression in outbred populations }\end{array}$ \\
\hline
\end{tabular}

are available; however, like any other cell, they have to ensure that their DNA is properly replicated without re-replication or copying errors, and that the replicated chromosomes are exactly segregated between the daughter cells. While this is in progress, transcription is restricted, so that only intact correctly copied genes are used to make RNA and proteins. Elucidation of the complex controls for monitoring the whole process is still in progress even in yeast $(1,2)$. The major components, although duplicated and somewhat diverged, are nevertheless highly conserved through evolution to higher eukaryotes $(3,4)$. Dividing human cells clearly have to achieve the same faultless standards of cell-cycle control, so that each tissue and organ grows to optimal size and then stops, apart from making necessary replacements where there is continuous cell-turnover (for example, in the gut, liver, or bone marrow). Loss of growth control, through mutation or viral invasion, leads either to cell death or to uncontrolled proliferationdegenerative disease or cancer.

Many of the genes identified in yeast that are required for tight cell-cycle control, including cyclins, cyclin-dependent kinases (CDKs), and inhibitors of CDKs $(1,2)$, have close homologues with very similar function in mammalian cells, and mutations in a number of these have been implicated in cancer (4). In the past couple of years, allele-loss studies in melanomas and a number of other tumors have led to the identification of the human cyclin dependent kinase inhibitor pl6 as a gene whose loss of function, possibly in conjunction with its closely linked relative p15, is involved in many different cancers. Rare germ-line mutations in pl6 (CDKN2) have been observed in families with a strong predisposition to melanoma (4). The pre-existing studies conducted in yeast immediately helped to illuminate the mechanisms of human disease when the involvement of pl6 and pl5 was determined by positional cloning efforts.

DNA sequence proof-reading and repair are also strongly conserved from bacteria, through yeast, to human. A number of genes mutated in families with hereditary nonpolyposis colon cancer (HNPCC) (5) were defined partly through the discovery that these tumors carry a high frequency of de novo mutations in simple repeat sequences, which are usually used as polymorphic genetic markers. One of the groups who identified some of the genes involved in these human tumors did so through knowledge of the genes involved in DNA repair in bacteria and yeast (6).

Different types of DNA damage are repaired by different nucleotide excision-repair enzymes. A failure to repair UV-dependent damage is the underlying cause of the various genetic forms of xeroderma pigmentosum (XP), and in each type (complementation group) of XP elucidated so far, a distinct gene from this pathway has been found to be mutated $(7,8)$. In most cases functional analysis was greatly helped by the fact that 
most of the genes were already well studied in yeast as yeast radiation-sensitivity $(R A D)$ genes.

The human gene mutated in ataxia telangiectasia $(A T M)$ was recently identified through positional cloning (9). ATM shows strong sequence homology to the yeast TELI and MECI genes, mutations which also confer increased sensitivity to DNA damage (10). The implied functional conservation suggests that appropriate mutants in yeast and other eukaryotes may be useful for understanding the disease mechanism and for suggesting approaches to therapy in ataxia telangiectasia.

The whole of the $S$. cerevisiae genome has been sequenced and is publicly available for sequence comparisons (11). Whenever an interesting gene is isolated in another species, yeast homologies can be identified and vice versa (12). If there is a yeast gene, but mutants are not available, they can readily be created in the hope that this will help in suggesting and exploring function in an experimentally amenable organism.

\section{CAENORHABDITIS ELEGANS: A SIMPLE DEVELOPMENTAL MODEL AND GENOME PROJECT PROTOTYPE}

This insignificant-looking, soil-dwelling nematode worm was recognized by Sidney Brenner in the mid-1960s as the ideal model system for studying development in close conjunction with genetics. The adult organism consists of just about 1,000 cells. The exact developmental derivation of each has been painstakingly elucidated (13). Developmental and behavioral mutants have been derived and mapped and many of the genes identified. The whole of the $\sim 100-\mathrm{kb}$ genome has been isolated in overlapping genomic clones, about $50 \%$ of which have now been sequenced in the original prototypic genome project (14). A surprising number of major principles in development have been shown to be conserved across the phyla from $C$. elegans to human. For example, although the concept of apoptosis was first noted in human tissue by clinically trained pathologists (15), the study of cell fate mutants in $C$. elegans has contributed enormously to elucidation of conserved genes involved in developmentally regulated and pathologically programmed cell death $(16,17)$.

In another key area, the simplicity of the nematode neural system has permitted dissection of axon guidance mechanisms. The possibil- ity of ready mutant selection and gene identification at affected loci has led to pathways defined by the uncoordinated series (unc genes). Most of the molecules involved turn out to be highly conserved in both sequence and function (18).

As the $C$. elegans genome sequence races to completion, many new genes without known function are being discovered. Where no known mutations map to the locus, functional gene knockouts can now be engineered by injecting antisense oligonucleotides into the worm germline and then looking for associated phenotype, which may provide insight into homologous human anomalies.

\section{DROSOPHILA MELANOGASTER: CONSERVED SIGNALS AND REGULATORS}

There are so many lessons to be learned from fruitflies that it is impossible to deal even with all the most notable cases. Homeotic genes constitute one of the best-known examples of genes first identified in Drosophila that have provided insight into mechanisms of human development and disease. These genes, which share conserved DNA-binding homeoboxes, are maintained in an ordered chromosomal array throughout many phyla, although in vertebrates there has been repeated duplication of the whole assembly. There has also been striking conservation in the axial patterns of orthologous gene expression. Hox genes are expressed in overlapping domains, generating a Hox-code which plays a major role in specifying the anteroposterior body plan from fly to mouse (19-21). There are virtually no recognized naturally occurring mammalian $H o x$ mutations, so they are being created by targeted gene knockout (see below) in the mouse. There is apparently some redundancy among Hox genes in mammals, since even homozygous loss of function at some loci has only relatively mild effects (22). However, recently, mild limb developmental phenotypes have been ascribed to heterozygous mutation in human HOXD13 (23) and mouse Hoxal3 (24), showing synpolydactyly and hypodactyly, respectively.

The eye is perhaps a more readily recognized functional unit than the anteroposterior axis. Surprisingly, since insect and vertebrate eyes are so different and have probably evolved independently (25), eye development has provided most important information on evolutionarily con- 
served mechanisms. Ironically, one of the earliest (most upstream) of transcriptional regulators controlling eye development, the PAX6 gene, was first defined in human and in mouse as the gene mutated in aniridia (absence of the iris) and in Small eye, respectively $(26,27)$. Subsequently, it was discovered that a Drosophila homologue exists, maps to the eyeless locus, and is functionally disrupted by transposon insertion in eyeless flies (28). Even more astonishingly, carefully controlled ectopic expression of either the fly gene or the mouse homologue in different Drosophila imaginal disks leads to the development of more or less normal eyes in ectopic sites such as on leg, wing, or antennae (29). This amazing conservation of function (and sequence) was a major spur to the reaffirmation of the concept of wide-ranging evolutionary gene conservation (30).

This idea is not new, but has been critical in the elucidation of many complexities in Ras and tyrosine kinase signaling pathways through the analysis of Drosophila eye mutants $(31,32)$. Insight into these pathways is important since they control aspects of human developmental regulation, hormone action, and cancer. Most recently, another type of signaling molecule, a homologue of the Drosophila segment polarity gene hedgehog, which is implicated as a gradient morphogen, was shown to be critical in human mid-line head development. Loss of one copy of the human sonic hedgehog $(S H H)$ gene can lead to holoprosencephaly, HPE3 $(33,34)$. One could not readily have guessed this genotype-phenotype association. Several other pieces in the jigsaw led to the identification of $S H H$ as the HPE3 gene: linkage analysis led to the $\mathrm{SHH}$ region of chromosome 7 (35) and the homozygous knockout phenotype for mouse $S H H$ (36) showed very severe HPE-like phenotype. Other components of this signaling pathway are also implicated in a very different human disease: mutations in the homologue of patched (PTCH), which functions as a hedgehog receptor (37), lead to nevoid basal cell carcinoma (38). It was amusing at a recent meeting to hear Drosophila geneticists getting excited about the possibilities of human genetics throwing light on fly gene function!

\section{ZEBRAFISH: A CLEAR MODEL FOR VERTEBRATE DEVELOPMENT}

Although developmental comparisons are readily made with Drosophila, there is considerable genomic expansion as we move to verte- brates and, as a result, there must be some alteration in gene function and evolution of some novel genes. This fecund fish, with the bonus of transparent embryos, provides an excellent model system for the isolation of a large number of developmental mutants. To this end several groups, most notably that of the Nobel laureate Christiane Nusslein-Volhard, who was recently honored for her work on Drosophila mutants, are about to publish the results of a saturation mutagenesis experiment aimed at deriving a series of developmental mutants (reviewed in refs. 39 and 40; also see the December 1996 issue of Development). The scene is now set to identify the mutant genes responsible for the new abnormal phenotypes. The genome revolution means that this will be possible in an organism which before this had very little genetics (40).

\section{MOUSE MUTANTS BY SELECTION AND MANIPULATION}

Despite the experimental usefulness of "lower" organisms, there remain endless reasons to continue using the laboratory mouse as the ideal model system for human disease. There are many cases where it is essential to use a mammalian system to understand the fine detail of developmental or metabolic pathways implicated in human disease. It is important to approximate as closely as possible the human physiological parameters in developing models where the aim is to elucidate and eventually treat human diseases. Many mouse mutants have been collected and genetically analyzed over the last five or six decades (41). Perhaps one good recent illustration of the usefulness of mouse models in unraveling developmental and metabolic control is our recently improved insight into obesity, appetite control, and energy metabolism, where positional cloning in mouse mutants has helped to uncover completely new pathways of gene interaction $(42,43)$. There is no doubt that the biotechnology industry considers this growth area well worth investing in.

For about the past 10 years it has also been possible to manipulate mouse embryos by insertion of special, totipotent embryonic stem (ES) cells at the blastocyst stage. These cells can contribute to the animal that is eventually born and in most cases the ES cell contribution will be propagated through the germline, so that breeding to homozygosity is possible. Over the past 
few years reliable techniques have been developed for creating inactivating mutations at specific gene loci by homologous recombination in ES cells. These are the famous mouse gene "knockouts," now comprehensively cataloged in an on-line database (44). Increasingly, techniques are becoming available to create very specific, single nucleotide mutations. In this way, models can be created for a high proportion of human diseases, allowing detailed functional analysis. Such models can be used to develop rational disease therapies. Most importantly, knockouts have been produced for interesting genes which had not previously been implicated in human disease, but where it was likely that loss of function mutations would produce mouse phenotypes reminiscent of recognizable human anomalies. The sonic hedgehog story above is a good illustration of how well this type of approach can work.

\section{HUMANS AS THE ULTIMATE MODEL}

There is no richer source of mutations than humankind, since so many variants and anomalies, from mild to severe ones, arise in our mainly outbred populations; these are carefully described, analyzed, and nurtured, and can be immortalized as permanent cell lines for long-term study at the DNA level. Improved genetic and physical mapping techniques have made possible increasingly rapid gene identification. Conserved synteny and gene order associations allow quick recognition of homologous human and mouse mutations, as in the case of aniridia and Small eye. There is much two-way traffic between different model systems, allowing the unraveling of complex interactive pathways. It is becoming increasingly clear that these pathways are generally highly conserved, so that analysis in one system can be extrapolated to another with sufficient confidence, at least to suggest novel experiments to check out the expected homology. Many human conditions give new insight into basic biology, as in the case of patched and hedgehog. Complex physiological pathways may also be illuminated in this way; for example, we have learned a great deal about ion channels from a wide spectrum of different diseases caused by mutations in these genes (45). This knowledge should lead to the development of some very finely tuned and specific drugs to ameliorate the conditions caused by these mutations.

\section{MODIFIERS REVEAL INTERACTING GENES}

Several of the organisms discussed here have excellent genetics, which can be used to search for modifier loci by looking for variants that alter the phenotype of a specified gene. These variants can be naturally occurring as in humans, or induced by mutagenesis in the model systems. In human populations the concept of interacting gene variants forms the basis of searches for multifactorial disease loci. Large-scale genetic analysis in selected populations or in affected sib pairs is required to track down and identify gene loci that travel with the disease phenotype (46). In yeast and Drosophila, the mutagenesis approach has been used very effectively to define genes in the same pathway. This is elegantly illustrated by the definition of signaling cascades required for Drosophila eye development (47). Large-scale mouse mutagenesis experiments are planned to search for new phenotypes for old diseases such as deafness and neurodegeneration (48). The genes involved will often be members of the same pathway.

Moving into the next millennium toward the end of the first phase of the genome projects, we are seeing an exciting era of biological consolidation and a much deeper understanding of the apparently universal underlying principles which govern the complex interactions required to support life across many phyla. Properly used, this knowledge should help to conserve and improve all aspects of life on earth.

\section{REFERENCES}

1. Stern B, Nurse P. (1996) A quantitative model for the cdc 2 control of $S$ phase and mitotsis in fission yeast. Trends Genet. 12: 345-350.

2. Nasmyth K. (1996) At the heart of the budding yeast cell cycle. Trends Genet. 12: 405412.

3. Orr-Weaver TL. (1994) Developmental modification of the Drosophila cell cycle. Trends Genet. 10: 321-327.

4. Harper JW, Elledge SJ. (1996) Cdk inhibitors in development and cancer. Curr. Opin. Genet. Dev. 6: 56-64.

5. Dunlop MG. (1996) Mutator genes and mosaicism in colorectal cancer. Curr. Opin. Genet. Dev. 6: 75-80.

6. Fishel RA, Lescoe MK, Rao MRS, et al. 
(1993) The human mutator gene homolog MSH2 and its association with hereditary nonpolyposis colon cancer. Cell 75: 10271093.

7. Hoeijmakers JHJ, Egly J-M, Vermeulen W. (1996) TFIIH: A key component in multiple DNA transactions. Curr. Opin. Genet. Dev. 6: 26-33.

8. Chu G, Mayne L. (1996) Xeroderma pigmentosum, Cockayne syndrome and trichithiodystrophy: Do the genes explain the diseases? Trends Genet. 12: 187-192.

9. Savitsky K, Bar-Shira A, Gilad S, et al. (1995) A single ataxia telangiectasia gene with a product similar to PI-3 kinase. Science 268: 1749-1753.

10. Morrow DM, Tagle DA, Shiloh Y, Collins FS, Hieter P. (1995) TEL1, an S. cerevisiae homolog of the human gene mutated in ataxia telangiectasia, is functionally related to the yeast checkpoint gene $M E C 1$. Cell 82: 831840.

11. Oliver SG. (1996) From DNA function to biological function. Nature 379: 597-600.

12. Hieter P, Bassett DE, Valle D. (1996) The yeast genome-a common currency. Nat. Genet. 13: 253-255.

13. Sulston JE, Schierenberg E, White JG, Thomsn JN. (1983) The embryonic cell lineage of the nematode Caenorhabditis elegans. Dev. Biol. 100: 64-119.

14. Hodgkin J, Plasterk RHA, Waterston RH. (1995) The nematode Caenorhabditis elegans and its genome. Science 270: 410-414.

15. Kerr JFR, Wyllie AH, Currie AR. (1972) Apoptosis: A basic biological phenomenon with wide-ranging implications in tissue kinetics. Br. J. Cancer 26: 239-257.

16. Horvitz HR, Shaham S, Hengartner MO. (1994) The genetics of programmed celldeath in the nematode Caenorhabditis elegans. Cold Spring Harbor Symp. Quant. Biol. 59: 377385.

17. Hengartner MO. (1996) Programmed cell death in invertebrates. Curr. Opin. Genet. Dev. 6: $34-38$.

18. Muller BK, Bonhoeffer F, Drescher U. (1996) Novel gene families involved in neural pathfinding. Curr. Opin. Genet. Dev. 6: 469-474.

19. Kenyon C. (1994) If birds can fly, why can't we? Homeotic genes and evolution. Cell 78: 175-180.

20. Krumlauf R. (1994) Hox genes in vertebrate development. Cell 78: 191-201.
21. Lawrence PA, Morata G. (1994) Homeobox genes: Their function in Drosophila segmentation and pattern formation. Cell 78: 181189.

22. St-Jacques B, McMahon AP. (1996) Early mouse development: Lessons from gene targeting. Curr. Opin. Genet. Dev. 6: 439-444.

23. Muragaki Y, Mundlos S, Upton J, Olsen BR. (1996) Altered growth and branching patterns in synpolydactyly caused by mutations in HOXD13. Science 272: 548-551.

24. Mortlock DP, Post LC, Innis JW. (1996) The molecular basis of hypodactyly (Hd): A deletion in Hoxal3 leads to arrest of digital arch formation. Nat. Genet. 13: 284-289.

25. Nilsson Dan-E. (1996) Eye ancestry: Old genes for new eyes. Curr. Biol. 6: 39-42.

26. Ton CCT, Hirvonen $H$, Miwa $H$, et al. (1991) Positional cloning and characterization of a paired box- and homeobox-containing gene from the aniridia region. Cell 67: 1059-1074.

27. Hill RE, Favor J, Hogan BLM, et al. (1991) Mouse Small eye results from mutations in a paired-like homeobox-containing gene. $\mathrm{Na}$ ture 354: 522-525.

28. Quiring R, Walldorf U, Kloter U, Gehring WJ. (1994) Homology of the eyeless gene of Drosophila to the Small eye gene in mice and aniridia in humans. Science 265: 785-789.

29. Halder G, Callaerts P, Gehring WJ. (1995) Induction of ectopic eyes by targeted expression of the eyeless gene in Drosophila. Science 267: 1788-1792.

30. Banfi S, Borsani G, Rossi E, et al. (1996) Identification and mapping of human cDNAs homologous to Drosophila mutant genes through EST database searching. Nat. Genet. 13: 167-174.

31. Chang HC, Karim FD, O'Neill EM, et al. (1994) Ras signal-transduction pathway in Drosophila eye development. Cold Spring Harbor Symp. Quant. Biol. 59: 147-1 53.

32. Dominquez M, Hafen E. (1996) Genetic dissection of cell fate specification in the developing eye of Drosophila. Semin. Cell Dev. Biol. 7: 219-226.

33. Roessler E, Belloni E, Gaudenz K, et al. (1996) Mutations in the human sonic hedgehog gene cause holoprosencephaly. Nat. Genet. 14: 357-360.

34. Dean M. (1996) Polarity, proliferation and the hedgehog pathway. Nat. Genet. 44: 245247.

35. Belloni E, Muenke $M$, Roessler E, et al. (1996) Identification of sonic hedgehog as a 
candidate gene responsible for holoprosencephaly. Nat. Genet. 14: 353-356.

36. Chiang C, Litingtung Y, Lee E, et al. (1996) Cyclopia and defective axial patterning in mice lacking sonic hedgehog gene function. Nature 383: 407-413.

37. Nusse R. (1996) Patching up hedgehog. Nature 384: 119-120.

38. Hahn H, Wicking C, Zaphiropoulos, et al. (1996). Mutations of the human homolog of Drosophila patched in the nevoid basal cell carcinoma syndrome. Cell 85: 841-851.

39. Granato M, Nusslein-Volhard C. (1996) Fishing for genes controlling development. Curr. Opin. Genet. Dev. 6: 461-468.

40. Felsenfeld AL. (1996) Defining the boundaries of zebrafish developmental genetics. Nat. Genet. 14: 258-263.

41. Darling S. (1996) Mice as models of human developmental disorders: Natural and artificial mutants. Curr. Opin. Genet. Dev. 6: 289294.

42. Spiegelman BM, Flier JS. (1996) Adipogen- esis and obesity: Rounding out the big picture. Cell 87: 377-389.

43. Chagnon YC, Bouchard C. (1996) Genetics of obesity: Advances from rodent studies. Trends Genet. 12: 441-444.

44. Jacobson D, Anagnostopoulos A. (1996) Internet resources for transgenic or targeted mutation research. Trends Genet. 12: 117118.

45. Keating MT, Sanguinetti MC. (1996) Pathophysiology of ion channel mutations. Curr. Opin. Genet. Dev. 6: 326-333.

46. Todd JA, Farrall M. (1996) Panning for gold: Genome-wide scanning for linkage in type 1 diabetes. Hum. Mol. Genet. 5: 1443-1448.

47. Karim FD, Chang HC, Therrien M, Wassarman DA, Laverty T, Rubin GM. (1996) A screen for genes that function downstream of rasl during Drosophila eye development. Genetics 143: 315-329.

48. Brown SDM, Peters J. Combining mutagenesis and genomics in the mouse-closing the phenotype gap. Trends Genet. 12: 433-435. 